Voix et Images

voixetimages

\title{
La Léthargie du cinéma québécois
}

\section{Gilles Thérien}

Volume 3, numéro 3, avril 1978

\section{Pierre Perrault}

URI : https://id.erudit.org/iderudit/200129ar

DOI : https://doi.org/10.7202/200129ar

Aller au sommaire du numéro

\section{Éditeur(s)}

Les Presses de l'Université du Québec

ISSN

0318-9201 (imprimé)

1705-933X (numérique)

Découvrir la revue

Citer cet article

Thérien, G. (1978). La Léthargie du cinéma québécois. Voix et Images, 3(3), 490-492. https://doi.org/10.7202/200129ar d'utilisation que vous pouvez consulter en ligne.

https://apropos.erudit.org/fr/usagers/politique-dutilisation/ 


\section{La Léthargie du cinéma québécois}

Au moment où s'étalent sur nos écrans deux films de Boisset, un Vadim, le dernier Buñuel, une pléiade, comme d'habitude, de films américains, on cherche en vain sa petite portion de films québécois. C'est à croire que la grève de la Presse et de Montréal-Matin empêche la sortie de nos prochains chefs-d'œuvre. Pas la moindre trace d'un film québécois dans le circuit commercial. Je ne parle pas des représentations gratuites de l'ONF à l'Outremont. En fait, le dernier film québécois que j'ai vu affiché, c'est Après-Ski à Bruxelles (s'il-vous-plaît) dans un cinéma "porno": (Merci, on repassera.) Pourtant on tourne et la très prodigieuse Société de développement de l'industrie cinématographique canadienne peut s'enorgueillir d'avoir mis au monde une excellente infrastructure de techniciens, des petits arrangements fiscaux qui ne font pas pleurer les investisseurs. La seule difficulté c'est que le film canadien de langue française se porte généralement mal... et de plus en plus mal et toujours grâce à cet organisme d'État dont le compétent président, Gratien Gélinas, passera à la postérité pour ses “Fridolinades». Depuis 1968, la SDICC a aidé à la production de 189 films $^{1}$ dont 80 québécois. Voyons voir:

1968 - 1970: 18 films dont ' 8 québécois

1970 - 1971: 27 films dont 10 québécois

1971 - 1972: 18 films dont 11 québécois

1972 - 1973: 34 films dont 12 québécois 


$1973-1974: 18$ films dont 7 québécois
$1974-1975: 23$ films dont 11 québécois
$1975-1976: 12$ films dont 5 québécois
$1976-1977: \quad 18$ films dont 7 québécois
en cours $: 21$ films dont 9 québécois

La moyenne est bonne: $42,3 \%$. Et il n'y aurait aucune matière à s'inquiéter si on restait aux chiffres généraux. Mais qu'advient-il si l'on veut savoir ce que recouvre ces $42,3 \%$. Surprise! Les 80 films peuvent se répartir de différentes façons:

1) par auteurs: 35 films sont faits par 9 cinéastes connus. Dans l'ordre: Héroux (8), Carle (6), Lefebvre (5), Lord (4), Arcand (3), Fournier (3), Brossard (2), Jutra (2), Labrecque (2). Ils ont été retenus parce qu'ils ont connu une certaine distribution commerciale.

2) par maisons de production: en général, les données se recoupent puisque les réalisateurs précịtés étaient en même temps producteurs. II faut faire une exception dans le cas des Productions Carle-Lamy qui sont responsables de Kamouraska et de Pour le meilleur et pour le pire de Jutra, de Gina d'Arcand, des Smattes de Labrecque, de même que Cinak (Lefebvre) est responsable outre ses films des deux premiers d'Arcand, de deux premiers longs métrages sans distribution commerciale. L'Association coopérative de production audio-visuelle (ACPAV) est responsable de 10 productions. 'C'est cette maison qui est responsable de l'utilisation de la plus grande diversité de réalisateurs. Malheureusemènt elle s'est vue aussi confier les plus petits budgets. Conclusion: peu de maisons ont accès aux ripailles.

3) par succès commerciaux sur place: l'initiation (Héroux); Deux Femmes en or (Fournier); Bingo (Lord).

Le reste, au dire des investisseurs, n'a pas eu le succès escompté Comprendre: un bon placement. En somme, on peut se demander si la disette actuelle au plan de la création ne vient pas du peu de réalisateurs. ayant accès au «gâteau financier» de même qu'au manque de flair de la SDICC. dans ses investissements. La noble société a voulu exercer un contrôle culturel... définir des contenus... etc. Or, comme d'habitude, les choses se sont faites un peu différemment. Devant des investisseurs, le carnet de chèques en main, on a dit oui, ce qui vaut l'honneur à la SDICC d'être au générique de Sept Fois par jour (Héroux) et d'être absente, pour refus « culturel», du générique des Dernières Fiançailles (Lefebvre). La bonne conscience est rachetée en aidant de jeunes cinéastes à se "casser la gueule " avec des budgets étriqués et l'absence (presque promise) de toute distribution commerciale. On espère donc (à haute voix) que des changements importants interviendront lorsque la société présentera son bilan. 
Depuis peu, moins d'un an, le Québec tente aussi par son Institut du film de venir en aide aux créateurs. Il est trop tôt pour juger de cette entreprise mais on peut déjà s'imaginer que les contrôles financiers seront soumis à d'autres priorités qu'à celles du développement du cinéma.

Si ces chiffres, ces indications statistiques sur la stagnation de l'industrie du cinéma sont de quelque utilité, c'est que nous sommes forcé de considérer que la création est en train de s'étioler alors que l'infrastructure est de plus en plus inféodée à la création étrangère. Altman tourne à Montréal, Chabrol vient agoniser sur notre sol, Simenon fils,... et plusieurs autres. Bientôt nous pourrons remplacer le Mexique, I'Espagne et la Yougoslavie. II est ironique que le besoin de contrer l'influence étrangère qui est à l'origine de l'action gouvernementale, devienne le fondement d'une nouvelle aliénation, plus grave encore, sur notre propre sol.

Quand l'industrie du long métrage démarre dans les années 1960, elle accompagne une effervescence de l'écriture dans le roman québécois. II est triste de noter que le fossé est allé grandissant entre ces deux moyens d'expression qui, dans tous les pays du monde, finissent par se retrouver. II est encore plus triste de voir que les créateurs du cinéma sont loin d'avoir acquis la maîtrise de leurs moyens, la maturité que l'on peut retrouver chez certains de nos romanciers qui vieillissent bien (dans le métier). Alors que l'écriture tend à devenir le lieu d'une réflexion, d'une recherche, le cinéma apparaît encore, sauf exception, comme le lieu du jeu et qui pis est, du jeu de hasard.

Gilles Thérien

1. Dernières statistiques du 11 janvier 1978. 